\title{
İhracat Engellerinin Kurumsal Kuram Perspektifinden Değerlendirilmesi (Evaluation of Export Barriers from the Institutional Theory Perspective)
}

\author{
Çiğdem BASKICI iD a, Yavuz ERCİL iD b \\ aBaşkent Üniversitesi, Sağlık Bilimleri Fakültesi, Ankara, Türkiye. cbaskici@baskent.edu.tr \\ bBaşkent Üniversitesi, İletişim Fakültesi, Ankara, Türkiye. yercil@baskent.edu.tr
}

\begin{tabular}{|c|c|}
\hline MAKALE BİLGİSİ & ÖZET \\
\hline $\begin{array}{l}\text { Anahtar Kelimeler: } \\
\text { Kurumsal Kuram } \\
\text { İhracat Engelleri } \\
\text { Uluslararasılaşma } \\
\text { Küçük ve Orta Büyüklükteki } \\
\text { İşletmeler }\end{array}$ & $\begin{array}{l}\text { Amaç - İşletmelerin karşılaştıkları ihracat engellerini ve bu engellerin ortadan kaldırılmasına } \\
\text { yönelik önerileri konu alan zengin bir uluslararasılaşma literatürü } 1980 \text { 'lerden itibaren oluşmaya } \\
\text { başlamıştır. Bununla birlikte farklı kurumsal çevrelerde faaliyet gösteren işletmelerin karşıştıkları } \\
\text { engellerin nedenlerine yönelik yeterli bir ilgi oluşmamıştır. Bu doğrultuda çalışmada, ihracat } \\
\text { engellerinin arkasındaki nedenlerin kurumsal kuram perspektifinden ortaya çıarılması } \\
\text { amaçlanmaktadır. Bu amacı gerçekleştirmek için "Ihracat engellerinin oluşmasına neden olan } \\
\text { kurumlar hangileridir?" sorusu cevaplandırılmıştır. }\end{array}$ \\
\hline $\begin{array}{l}\text { Gönderilme Tarihi } 12 \text { Mart } 2019 \\
\text { Revizyon Tarihi } 28 \text { Ağustos } \\
2019\end{array}$ & $\begin{array}{l}\text { Yöntem - Çalışma ihracat deneyimine sahip ve ana faaliyetlerini Ankara'da yürüten } 23 \text { KOBI'yi } \\
\text { kapsamaktadır. Kelly's Rep testi ve açı uçlu sorularla toplanan veriler içerik analizi ile } \\
\text { değerlendirilmiştir. Böylece işletmelerin karşılaştıkları ihracat engelleri ve bu engellerin arkasındaki } \\
\text { kurumlar tespit edilmiştir. }\end{array}$ \\
\hline $\begin{array}{l}\text { Makale Kategorisi: } \\
\text { Araştırma Makalesi }\end{array}$ & $\begin{array}{l}\text { Bulgular - Çalışmanın bulguları farklı düzeylerde de olsa hem düzenleyici hem de bilişsel ve } \\
\text { normatif kurumların ihracat engellerinin (kaynak engelleri, bilgi ve deneyim engelleri, prosedür } \\
\text { engelleri ve dış kaynaklı engeller) ortaya çıkmasında etkili olduğunu göstermektedir. Diğer bir ifade } \\
\text { ile engellerin nedenlerinin somut boyutlarının yanında farkındalık ya da değer yargıları gibi soyut } \\
\text { boyutları da vardır. }\end{array}$ \\
\hline & $\begin{array}{l}\text { Tartışma - Çalışma ile literatüre ihracatın önündeki engellerin nedeni olarak kurumların incelendiği } \\
\text { bir bakış kazandırılmıştır. Çalışma sonuçları: i) engellerin kendilerini ortaya çıaran kurumlara } \\
\text { bağlı olarak dinamizm sergilediklerini, ii) engelleri ortadan kaldırmaya yönelik politikaların hem } \\
\text { düzenleyici hem de bilişsel ve normatif kurumların etkilerini gözetecek şekilde kapsayıcı olması } \\
\text { gerektiğini, iii) engelleri ortadan kaldırmaya yönelik jenerik politikaların üretilmesinin zor } \\
\text { olduğunu ve vaka özelinde politika uygulamalarına gidilmesinin önemini ortaya koymaktadır. }\end{array}$ \\
\hline
\end{tabular}

\begin{tabular}{|c|c|}
\hline ARTICLE INFO & ABSTRACT \\
\hline $\begin{array}{l}\text { Keywords: } \\
\text { Institutional Theory } \\
\text { Export Barriers } \\
\text { Internationalization } \\
\text { Small and Medium-Sized } \\
\text { Enterprises }\end{array}$ & $\begin{array}{l}\text { Purpose - Since the 1980s, a rich literature on internationalization addressing the export barriers } \\
\text { facing enterprises and recommendations for eliminating them has emerged. However, there is } \\
\text { scarce information about the causes of the barriers faced by the enterprises operating in different } \\
\text { institutional environments. In this respect, the study aims to reveal the reasons behind export } \\
\text { barriers from institutional theory perspective. In order to achieve this aim, the question of "Which } \\
\text { institutions cause export barriers?" was answered. }\end{array}$ \\
\hline $\begin{array}{l}\text { Received } 12 \text { March } 2019 \\
\text { Revised } 28 \text { August } 2019\end{array}$ & $\begin{array}{l}\text { Methodology - The study includes } 23 \text { SMEs which are located in Ankara and experienced in } \\
\text { exporting. The data were collected by Kelly's REP test then answers were analyzed by conten } \\
\text { analysis. Thus, the institutions behind the export barriers that enterprises are faced with were } \\
\text { identified. }\end{array}$ \\
\hline $\begin{array}{l}\text { Article Classification: } \\
\text { Research Article }\end{array}$ & $\begin{array}{l}\text { Findings - The findings of the study show that all regulatory and cognitive and normative } \\
\text { institutions are effective in the emergence of export barriers (resource barriers, knowledge and } \\
\text { experience barriers, procedure barriers and exogenous barriers), albeit at different levels. In other } \\
\text { words, the causes of the barriers have concrete dimensions as well as abstract dimensions such as } \\
\text { awareness or value judgments. }\end{array}$ \\
\hline & $\begin{array}{l}\text { Discussion - The study provides a view about examining institutions as the cause of exports } \\
\text { barriers to the literature. Results of this study reveal that i) the barriers exhibit dynamism depending } \\
\text { on the institutions that cause them, ii) the policies aimed at eliminating the barriers should be } \\
\text { inclusive of all regulatory and cognitive and normative institutions, iii) since it is difficult to execute } \\
\text { generic policies to eliminate the barriers case-specific policies should be implemented. }\end{array}$ \\
\hline
\end{tabular}




\section{Giriş}

İhracat, yabancı pazarlara giriş yöntemleri arasında uluslararasılaşmaya kalkışmanın en hızlı ve en basit yolu olarak görülmekte (Johanson ve Vahlne, 1990) ve işletmeler için çok çeşitli fırsatlar yaratabilmektedir. İşletmeler ihracat ile ülke pazarlarının sayısını arttırma ve pazarla ilgili riski azaltma fırsatlarını yakalar, ana ülkelerindeki fazla üretim kapasitesinden yararlanır ve üretim verimliliğini artırır, gelirini çeşitlendirerek finansal konumunu iyileştirebilir, rekabet avantajı sağlayabilir ve yönetim becerilerini geliştirebilir (ArteagaOrtiz ve Rubén Fernández-Ortiz, 2010; Gao vd., 2010; Leonidou, 2000; Morschett vd., 2010; Sullivan ve Bauerschmidt, 1988). Dolayısıyla yarattığı birçok fayda ile ihracat, karar vericiler tarafından gerçekleştirilmek istenen ekonomik bir faaliyettir (Leonidou, 2000). Bununla birlikte işletmelerin ihracata başlaması veya mevcut ihracat faaliyetlerini artırması yalnızca işletmelerdeki karar vericilerin değil, ülke düzeyindeki karar vericilerin de gündemindeki önemli bir meseledir. Hükümetler ihracatı artırmak için ihracat teşvik ajansları kurmakta, düzenlemeler veya kanunlarla ihracat yapan işletmeleri desteklemektedir (Francis ve Collins-Dodd, 2004; Freixanet, 2012; Kang, 2011; Luo vd., 2010; Wang vd., 2017). Devletlerin işletmelerin uluslararasılaşmasını desteklemelerindeki temel motivasyonu, yerel ekonominin dış dünya ile bağlantısının dış pazarlara doğru genişlemek isteyen işletmeler aracıllğıyla olduğuna yönelik farkındalıklarıdır (Bazuchi vd., 2013: 418).

Hem işletmeler hem de devlet tarafından ihracata ilişkin ortaya konulan çabalar, ihracatın önündeki engellere yönelik literatürde geniş bir çalışma alanı yaratmıştır. İşletmelerin ihracat konusundaki bilgileri, kapasiteleri ve geliştirilmesi gerekli görülen yetkinlikleri çerçevesinde engeller; detaylı bir şekilde ele alınıp sınıflandırılmış, uzun ve standardize edilmeye çalışılan listeler ve çözüm önerileri ortaya çıkmıştır (Katsikeas ve Morgan, 1994; Leonidou, 2004; Roy vd., 2016; Suàrez-Ortega, 2003). Ancak ülkeler düzeyinde tespit edilen engeller benzer gibi gözükse de engellerin kaynaklarının farklı olacağının dikkate alınması gerektiği savunulabilir. Dolayısıyla listeler haline getirilen engellerin her ülke için aynı ağırlığa ve çözüme sahip olması her zaman geçerli olmayabilir. Bu sebeple engellerin ortadan kaldırılmasına yönelik çabaların netice vermesi öncelikle engellerin nedenlerinin doğru anlaşılmasını gerektirmektedir. Bununla birlikte literatürdeki tespit ve değerlendirmelere karşın pratikte bu alanda sürekli yeni ihtiyaçlar gözlemlenmektedir. Devletler, sivil toplum örgütleri ve işletme grupları bu konuda yeni taleplerle bilim dünyasının karşısına çıkmaktadır. Bu durum yukarıda ifade edilen gereksinimi daha da güçlendirmektedir.

Bu çalışmada literatürde ortaya konulan ihracat engellerinin nedenlerinin kurumsal kuram perspektifinden ele alınması gerektiği savunulmaktadır. Böyle bir iddianın temel dayanak noktası her ülkenin farklı bir kurumsal çevreye sahip olması ve işletmelerin faaliyetlerinde içine gömüldükleri bu çevreden etkilendiği gerçeğidir (Hitt vd., 2004). Kurumsal çevre; işletmelerin davranış ve seçimlerini etkileyen, bazı davranışları kolaylaştırırken bazı davranışları zorlaştıran, davranışa yönelik yasak koyan veya motive eden, iş yapma konusunda bilgi birikimini ve sosyal normları, inançları temsil eden yapılar bütününden oluşur (Scott, 1995). İhracat engelleri bahsi geçen yapının zorlayıcı, psikolojik veya bilişsel bir süreç çıktısı olarak değerlendirilebilir. Çalışmada kurumsal kuram ihracat engellerinin nedenlerinin ortaya konulmasını sağlamanın bir aracı olarak kullanılmışır.

“İhracat engellerinin oluşmasına neden olan kurumlar hangileridir?" sorusu çalışmanın odağında yer almaktadır. Küçük ve orta büyüklükte işletmeler (KOBİ) üzerinde bir araştırma tasarlanarak bu sorunun yanıtı aranmıştır. Araştırmanın KOBI'lerde yapılmasının temel sebebi büyük işletmelerin aksine KOBI'lerin sınırlı içsel kaynaklardan ve kabiliyetlerden dolayı faaliyet gösterdikleri kurumsal çevreden kaynaklı daha güçlü baskılara maruz kalmasıdır (Shirokova ve Tsukanova, 2013). Ayrıca KOBİler ihracat engellerinden büyük işletmelere göre daha fazla etkilenmektedir (Morgan ve Katsikeas, 1997) ve bu nedenle KOBİ'lerin karşılaştıkları ihracat engellerinin arkasındaki nedenlerin anlaşılması hem teori hem de pratik için önem kazanmaktadır. Araştırmada, ana faaliyetlerini Ankara'da yürüten 23 KOBİ yöneticisi ile yüz yüze görüşme yapılmıştır. Öncelikle yöneticilere Kelly's Rep testi uygulanmıştır. Bu test sayesinde yöneticiler açısından engellere yönelik bir değerlendirme yapılmıştır. Sonrasında yöneticilere yöneltilen açık uçlu soruların içerik analizi ile bu engellere neden olan kurumlar tespit edilmiştir.

İzleyen kısımda Kelly's Rep testinde kullanılacak ihracat engellerine temel oluşturan literatür taraması ile çalışmanın kavramsal çerçevesini oluşturan kurumsal kuram aktarılmaktadır. Bu kısmı çalışmanın yönteminin anlatıldığı ve veri kaynağının tanımlandığı kısım izlemektedir. Bulgular kısmında analiz 
sonuçları sunulmaktadır. Son olarak ulaşılan sonuçlara ve gelecek çalışmalarla ilgili çeşitli önerilere yer verilmektedir.

\section{Kavramsal Çerçeve}

\section{İhracat Engelleri}

Uluslararasılaşma bir işletme için hem rekabetçi güç hem de sürdürülebilir büyüme açısından çok önemli bir hamledir (Cahen vd., 2016; Neupert vd., 2006; Pinho ve Martins, 2010; Roy vd., 2016; Rutashobya ve Jaensson, 2004). Ancak işletmeler bu süreçte çeşitli engeller ile karşılaşabilmektedir. Bir işletmenin uluslararasılaşmasının ilk aşaması olarak görülen ihracatın önündeki engeller; işletmenin denizaşırı pazarlara girmesini, bu pazarlarda gelişmesini veya işletme operasyonlarını sürdürme kabiliyetini engelleyen sinırlamalar olarak tanımlanmaktadır (Leonidou, 2004).

İhracatın önündeki engeller üzerine yapılan çok sayıdaki çalışma bir dizi kesin bulgu ve buna bağlı sınıflandırmalar ortaya çıkarmıştır. Bununla birlikte literatürde yaygın bir biçimde kullanılanı Leonidou (2004) tarafından yapılan sınıflandırmadır ve içsel engeller ile dışsal engeller olarak iki ana başlık altında kategorize edilmiştir. İçsel engeller bilgisel, fonksiyonel ve pazarlama başlıkları altında ayrıntılandırılırken dışsal engeller prosedürel, resmi, görev ve çevresel engeller olarak dört alt başlıkta ele alınmıştır. Buna benzer bir sınıflandırma Kahiya (2013) tarafından yapılmıştır. İçsel engeller; kaynak, yönetimsel ve bilgi ilişkili engeller; dışsal engeller ise ana ülke temelli pazar engelleri, ev sahibi ülke temelli engeller ve endüstri düzeyindeki engeller şeklinde tanımlanmıştır. Arteaga-Ortiz ve Fernández-Ortiz (2010) bilgi engelleri, kaynak engelleri, prosedür engelleri ve dış kaynaklı engellerden oluşan dörtlü bir sınıflandırma önermişlerdir. Kahiya vd. (2014) çalışmalarında içsel ve dışsal engellere kontrol edilen/edilemeyen ve statik/dinamik olma boyutlarını ekleyerek çok düzeyli bir engeller sınıflandırması yapmışlardır. Çok düzeyli bir sınıflandırma da Kaprálová (2017) tarafından yapılmıştır. İç ve dış engel tipolojisini yerli ve yabancı engel tipolojisi ile birleştirerek dörtlü bir kategorizasyon oluşturmuştur: içsel-yerli, içsel-yabancı, dışsal-yerli ve dışsal-yabancı. Paul vd. (2017) ihracatla ilgili engelleri makro ve mikro problemler olarak sınıflandırmışlardır. Makro problemler politik istikrarsızlık ve yetersiz talep gibi işletmenin kontrolünün ötesinde olan faktörlerden kaynaklanmaktadır ve işletme için dışsal engellerdir. Mikro problemler ise ihracat biriminin zayıf organizasyonu, kaynak ve sermaye yetersizliği, uluslararası deneyimin zayıflığı gibi işletmenin kendisinden kaynaklanan ve kontrol edilmesi daha mümkün içsel engellerdir. Literatürde bu tarz sınıflandırmalara ilişkin örnekleri çoğaltmak mümkün olmakla birlikte genel eğilim engelleri içsel ve dışsal olarak kategorize etmeye yönelik gibi görünmektedir.

Yapılan ampirik çalışmalar engellerin işletmeler üzerindeki etkilerinin; işletmenin ihracatın hangi aşamasında olduğu, hangi sektörde faaliyet gösterdiği, büyüklüğü, menşe ülkesi (gelişmiş/gelişmekte olan) gibi çeşitli değişkenlere bağlı olduğunu göstermektedir. Örneğin Leonidou (2000) 100 Kıbrıslı ihracatçı üzerinde yaptığı çalışmada birkaç senedir piyasada faaliyet gösteren genç işletmelerin deneyimli olanlara göre; tüketici malları üreten işletmelerin endüstriyel ürün üretenlere göre ve daha küçük ve daha az kârlı işletmelerin diğerlerine göre ihracat engelleri karşısında daha kırılgan olduklarını bulmuştur. Katsikeas ve Morgan (1994) işletme büyüklüğü ve ihracat deneyiminin işletmelerin ihracat engellerini algılamada kritik olduğunu destekler sonuçlara ulaşmışlardır. İnan ve Nakıboğlu (2009) ihracat engellerinden bazılarının algılanma düzeyinin işletmelerin büyüklüklerinden, ihracat deneyimlerinden ve ihracat oranlarından etkilendiğini bulmuşlardır. Bununla birlikte Silva vd. (2016) ihracat engellerinin önemini, endüstri türleri ve işletme büyüklüklerini kıyaslayarak araştırmışlardır. Çalışmalarında ihracat engellerinin önemine ilişkin endüstri etkisi tanımlayabilmişlerken büyüklük etkisi tanımlayamamışlardır. Kahiya ve Dean (2016) Yeni Zelanda'daki işletmeler ile yaptıkları araştırmada kaynak kısıtlamalarının, bilgi ve tecrübe, pazarlama ve ihracat prosedürü engellerinin işletmelerin ihracat aşamaları ile ilişkili olduğunu keşfetmişlerdir. Kaynak kısıtlamalarının, pazarlama ve ihracat prosedür engellerinin etkisi genellikle ihracat süreçlerinin daha ileri aşamalarındaki işletmeler için daha yüksektir. Bununla birlikte bilgi ve deneyim engelleri genellikle ihracat süreçlerinin daha ileri aşamalarındaki işletmeler tarafından daha az etkili algılanmaktadır. Suàrez-Ortega (2003) bilgi, kaynak, prosedür ve dış kaynaklı engellerin algılanan öneminin işletmenin ihracat gelişim düzeyi ile ilişkisini araştırmıştır. Buna göre her bir engel türünün nispi önemi işletmenin ihracat gelişim aşamasıyla beraber değişmektedir. İhracatla ilgilenmeyen işletmeler için kaynak engelleri en önemliyken ihracat yapmayan ancak ihracatla aktif olarak ilgilenen işletmeler için bilgi engelleri diğer engellerden daha 
kritiktir. İhracatın ilk aşamasındaki işletmeler ile deneyimli işletmeler arasında engeller açısından en büyük fark prosedürel engellerde ortaya çıkmıştır. Bu çalışmalar ihracat engellerinin sadece ihracata başlama ile ilgili olmadığını da göstermektedir (Leonidou, 2004). İşletmeler yabancı pazara girseler de pazar payı elde etme, operasyonlarını genişletme veya daha fazla performans gösterme mücadelesinde çeşitli engellerle karşılaşmaya devam etmektedir (Mavrogiannis vd., 2008).

\section{Kurumsal Kuram}

İşletmelerin stratejik kararlarının değerlendirilmesinde geleneksel olarak iki baskın paradigma mevcuttur. İlki endüstri içindeki koşulların büyük ölçüde işletme stratejilerini belirlediğini iddia eden endüstri-temelli bakıştır (Porter, 1980). Hayatta kalmak ve başarılı olmak isteyen işletmeler hızla değişen endüstri çevresinin uyguladığı güçlü baskılara adapte olmak ve stratejik seçimlerini bu doğrultuda yapmak zorundadır (Ju vd., 2014). Diğer bir ifade ile dışsal çevreye olan bağımlılık işletmelerin stratejik seçimlerinde kısıtlamalara neden olurken işletmeler uygun stratejiler geliştirerek bağımlılıklarını yönetebilir (Gao vd., 2010). Endüstri-temelli bakışa göre yeni girişimlerin uluslararasılaşma stratejileri büyük ölçüde faaliyet gösterdikleri endüstrinin rekabetçilik derecesine dayanmaktadır (Yamakawa vd., 2008).

Stratejik kararların değerlendirilmesinde kullanılan ikinci baskın paradigma kaynak-temelli bakıştır (Barney, 1991). Kaynak-temelli bakış literatürü; benzersiz, nadir, taklit edilemeyen ve ikame edilemeyen kaynakların rekabetçi avantajın kaynağı olduğunu savunmaktadır (Barney, 1991). Bu bakış, bahsi geçen nitelikteki işletmeye özel kaynakların stratejiyi ve performansı harekete geçirdiğini iddia etmektedir (Barney, 1991; Teece vd., 1997).

Stratejik işletme davranışına yönelik endüstri-temelli ve kaynak-temelli bakışlar güçlü kavrayışlar sağlamakla birlikte kurumları büyük ölçüde dikkate almadıkları, arka plan olarak varsaydıkları (Peng vd., 2008) konusunda eleştirilmektedir. Özellikle gelişmekte olan ekonomilerde işletme stratejileri ve performanslarının kurumlar tarafından etkilendiğine dair artan araştırma kanıtları anılan eleştiriler için güçlü bir zemin oluşturmuştur. Literatüre bakıldığında iki temel alanın kurumlara farklı perspektiflerle yaklaştığ görülmektedir. İktisatçılar kurumlar olarak kanunlar, kurallar ve düzenlemeler gibi formel kurumlardan bahsederken sosyologların ilgi alanındaki kurumlar daha çok informel özelliklere sahip olan kültür, değer ve normlardır (Peng vd., 2009). Sosyologlar informel kurumların meşruiyet rolüne odaklanırken iktisatçılar formel kurumların etkinlik rolüne odaklanmaktadırlar (Bruton ve Ahlstrom, 2003; Garrido vd., 2014; Peng, 2002). Formel kurumlar açık kurallara işaret eder ve bunlar açıkça bir otorite tarafından kurulmalıdır (Garrido vd., 2014). İnformel kurumların kaynağı ise sosyo-kültüreldir (Cardoza vd., 2012).

Kurumsal kuramda alanında iki öncü çalışma (North, 1990; Scott, 1995) formel ve informel kurumları birlikte dikkate alarak bütüncül bir bakış açısı sunmuştur (Peng vd., 2009). Kurumsal iktisatçı Douglass North, kurumları bir oyunun formel ve informel kurallarına benzetmektedir (North, 1990: 3) ve bunlar "politik, ekonomik ve sosyal etkileşimi şekillendiren insan eliyle yapılmış/icat edilmiş kısıtlamalar"dır (North, 1991: 97). Bu bakışla zaman içinde kurumlar, diğerlerine göre bazı davranışları teşvik eden kurallar geliştirir. Sosyolog W. Richard Scott (1995: 33) kurumları "sosyal davranışa istikrar ve anlam sağlayan düzenleyici, normatif ve bilişsel yapılar ve faaliyetler" olarak tanımlamaktadır. Düzenleyici kurumlar belirli davranışları teşvik eden veya bunları yasaklayan kanun ve düzenlemelerken bilişsel kurumlar bir ülkedeki kişilerin bilgi ve yetenekleri; normatif kurumlar ise ulusal düzeyde iş gelişimini etkileyen ve sosyal olarak paylaşılan sosyal normlar, değerler, inançlar ve varsayımlardır (Scott, 1995: 35-45).

Kurumsal kuram; işletmelerin içine gömüldüğü kurumsal çevrenin formel ve informel boyutları ile işletme davranış ve seçimlerini, örgütsel uygulama, tasarım ve yapılarını etkilediğini savunmaktadır (Munir, 2002; Shirokova ve Tsukanova, 2013). Diğer bir ifade ile işletmeler uygun ekonomik davranışı belirleyen ve stratejik tercihleri etkileyen normlar ve değerler çerçevesi ile düzenleyici kurallara gömülmüştür (Hitt vd., 2004: 174). Kurumlar bir taraftan işletmelerin davranışlarını düzenlerken diğer taraftan da davranışa yönelik motivasyonunu artırmakta veya azaltmaktadır (Hitt vd., 2004: 173). Kısaca kurumsal kuram, işletme stratejik seçimlerini kurumlar ve örgütler arasındaki etkileşimin bir çıkısı olarak görmektedir (Gao vd., 2010; Peng vd., 2009; Peng vd., 2008). 


\section{Yöntem}

Çalışmanın amacı ihracat engellerinin arkasındaki nedenleri kurumsal kuram perspektifinden ortaya çıkarmaktır. Bu doğrultuda nitel araştırma modellerinden olgubilim modeli kullanılmıştır. Araştırmada ihracat engelleri araştırma olgusu olarak tanımlanmış ve bu olguya ilişkin bireysel bakış açıları tespit edilmiştir. Böylece katılımcıların belirli bir zamanda ve belirli bir bağlam içinde ihracat engellerini nasıl algıladıkları kurumsal kuram perspektifinden ortaya konmuştur.

Araştırmanın temel kavramları olan ihracat engelleri ve kurumlar yazarlar tarafından literatür referanslarına bağlı olarak tanımlanmıştır. Bu kapsamda ihracat engelleri; kaynak engelleri, bilgi ve deneyim engelleri, prosedür engelleri ve dış kaynaklı engeller (Kahiya vd., 2014) olarak araştırmaya dahil edilmiştir. Kurumlar ise bilişsel, düzenleyici ve normatif kurumlar (Scott, 1995) şeklinde belirlenmiştir.

\section{Örneklem, Verilerin Toplanması ve Analiz}

Araştırmada ihracat engellerinin arkasındaki nedenlerin derinlemesine anlaşılabilmesi ve incelenebilmesi için amaçlı bir örneklem seçilmiştir (Patton, 2002). Amaçlı örneklemler, en yaygın kullanılan olasılıksız örnekleme şeklidir ve büyüklükleri genellikle "doygunluk" kavramına dayanır (Guest vd., 2006). Doygunluk noktasında yapılacak yeni görüşmelerde yeni enformasyon ve temalar gözlenmez ve bu kavram nitel araştırmalarda örneklem büyüklüğünün belirlenmesi açısından yararlıdır (Boddy, 2016). Bununla birlikte doygunluğa ulaşmak için gereken örneklem büyüklüğünü tahmin etmek için yayınlanmış bir kılavuz veya yeterlilik testi yoktur (Morse, 1995). Dolayısıyla örneklemin büyüklügü araştırma esnasında kesinlik kazanmaktadır. Araştırmanın yapısıyla uyumlu olarak ulaşılması hedeflenen kesim ihracat deneyimine sahip KOBİlerdir. Çünkü büyük işletmelerin aksine KOBİler sınırlı içsel kaynaklardan ve kabiliyetlerden dolayı faaliyet gösterdikleri kurumsal çevreden kaynaklı daha güçlü baskılara maruz kalmaktadır (Shirokova ve Tsukanova, 2013) ve dolayısıyla kurumların bu işletmelerin karşılaştıkları ihracat engelleri üzerindeki etkisinin daha net görülebileceği beklenmektedir. Bununla birlikte katılımcılar açısından belirli bir düzeyde homojenlik sağlanması amaçlanmıştır. Katılımcıların araştırma alanındaki deneyimleri ne kadar birbirine benzerse araştırma doygunluğuna o kadar hızlı ulaşılabilir (Guest vd., 2006). Bu sebeple araştırma için seçilen KOBI'ler Ankara'da aynı organize sanayi bölgesinde faaliyet gösteren işletmelerdir.

Veri toplama sürecine başlayabilmek için ilk aşamada her bir hedef işletme ile telefon görüşmesi yapılarak araştırmanın amacı ve kapsamı açılanmıştır. Telefon görüşmelerinde işletmenin ihracat deneyimi sorgulanmış, bu konudaki birikimin kim tarafından temsil edildiği öğrenilmiş ve araştırma kapsamındaki beklentiler kendilerine açıklanmıştır. Böylece araştırma için işletmelerdeki en uygun katılımcıların bulunması da mümkün hale gelmiştir. İkinci aşamada yüz yüze görüşmeler yapmak için işletme yöneticileri ile randevular düzenlenmeye başlanmıştır. Araştırmada istatistiksel olarak anlamlı bir büyüklükteki örneklemden standartlaştırılan bir bilgiden ziyade, araştırma sorusunun cevabını verebilecek zenginlikte bilginin edinilmesi esas alınmıştır (Patton, 2002). Araştırmada 24. görüşmeden itibaren ortaya çıkan bilgiler örneklemeye eklemeler yapmanın faydalı olmayacağını, diğer bir ifade ile veri doygunluğuna ulaşıldığını göstermiş ve örneklem büyüklüğü 23'te kesilmiştir. 12.09.2018 tarihinde başlayan görüşmeler 20.11.2018 tarihinde son bulmuştur. Kelly's Rep testi ve açık uçlu soruların kullanıldığı veri toplama süreci katılımcı başına ortalama olarak 45 dakika sürmüştür. Rep testi inceleme konusuna ilişkin değerlendirmeleri, ilgili konunun temel kavramları üzerinden karşılaştırmalarla ortaya çıkaran psikososyal bir yöntemdir (Kelly, 1955).

Araştırmanın tasarımı içinde ilk adım yöneticilerin karşılaştıkları ihracat engellerini zorlukları açısından önceliklendirmelerini sağlamak olmuştur. Bu doğrultuda Kelly's Rep testi kullanılarak kaynak engelleri, bilgi ve deneyim engelleri, prosedür engelleri ve diş kaynaklı engellerin üçlü kombinasyonları oluşturulmuştur. Yöneticilerin her kombinasyondan kendileri için aşılması en zor engeli belirlemeleri istenmiştir. Sonrasında yöneticilere üç açık uçlu soru yöneltilmiştir. Bunlardan ilki önceliklendirdikleri engelleri neden en zor engel olarak gördükleri, ikincisi bu engellerin kaynaklarının neler olabileceği ve son olarak bu engelleri aşmakta neden zorlandıklarıdır. Böylece yöneticilerin belirledikleri engellerin nedeni olan kurumların ortaya çıkarılması hedeflenmiştir. Bu doğrultuda yöneticilerin verdikleri cevaplar üzerinden içerik analizi yapılmıştır. İçerik analizinde kodlama çerçevesini bilişsel, düzenleyici ve normatif kurumlar oluşturmuştur. Kodlamalar nitel araştırma ve kurumsal kuram alanlarında uzmanlaşmış 7 kişi 
tarafından yapılmıştır. Buna göre kurumsal kuram çerçevesinde yapılan kodlamaların \%13'ü konusunda kodlamayı yapanlar arasında ortak bir yargıya varılamamıştır. Analizler birbirini destekleyen \%87'lik kısım üzerinden yapılmıştır.

\section{Bulgular}

Yöneticiler için ihracat engellerinin zorluk sıralamasının ne olduğunun araştırılması ile başlayan çalışmada öncelikle Kelly's Rep testine uygun olarak engeller zorlukları açısından birbirleriyle kıyaslanmıştır. Bunun için her bir engel ikili karşılaştırmaya tabi tutulmuştur ve yöneticiler tarafından tercih edilen engelin zorluk oranı belirlenmiştir (Tablo 1). Buna göre kaynak engelleri dış kaynaklı engellerden \%53,3, bilgi ve deneyim engellerinden $\% 53,6$, prosedür engellerinden ise $\% 55,9$ daha zor aş1labilir görülmüştür. Diş kaynaklı engeller ise bilgi ve deneyim engellerinden $\% 52,9$, prosedür engellerinden $\% 64$; bilgi ve deneyim engelleri ise prosedür engellerinden $\% 56,5$ daha zor aşılabilir görülmüştür.

Tablo 1. İhracat Engellerinin Karşılıklı Kıyaslamaları (\%)

\begin{tabular}{lcccc} 
& $\begin{array}{l}\text { Kaynak } \\
\text { engelleri }\end{array}$ & $\begin{array}{l}\text { Diş kaynaklı } \\
\text { engeller }\end{array}$ & $\begin{array}{l}\text { Bilgi ve deneyim } \\
\text { engelleri }\end{array}$ & $\begin{array}{l}\text { Prosedür } \\
\text { engelleri }\end{array}$ \\
\hline Kaynak engelleri & & 53,3 & 53,6 & 55,9 \\
Diş kaynaklı engeller & & 52,9 & 64,0 \\
Bilgi ve deneyim & & & 56,5 \\
engelleri & & & \\
Prosedür engelleri & & & \\
\hline
\end{tabular}

Tablo 1 oluşturulduktan sonra engellerin zorluk sıralaması belirlenmiştir (Tablo 2). Buna göre yöneticiler için ihracatın önündeki aşılması en zor engel kaynak engelleridir. Bunu çok yakın bir oranla dış kaynaklı engeller takip etmektedir. Üçüncü sırada bilgi ve deneyim engelleri, son sırada prosedür engelleri yer almaktadır.

Tablo 2. İhracat Engellerinin Zorluk Sıralaması

\begin{tabular}{ll} 
Engeller & Zorluk siralaması \\
\hline Kaynak engelleri & 0,29 \\
Dış kaynaklı engeller & 0,28 \\
Bilgi ve deneyim engelleri & 0,23 \\
Prosedür engelleri & 0,20 \\
\hline
\end{tabular}

Araştırmada ihracat engellerinin zorluk sıralaması belirlendikten sonra yöneticiler tarafından bu engellerin oluşmasına neden olarak görülen kurumlar tespit edilmiştir. Tablo 3'e göre ihracat engellerinin kaynağ 1 olarak görülen kurumların \%38'i bilişsel, \%36'sı düzenleyici ve $\% 26$ 'sı normatiftir.

Tablo 3. İhracat Engellerinin Arkasındaki Kurumlar

\begin{tabular}{lccc} 
& Bilişsel kurumlar & Düzenleyici kurumlar & Normatif kurumlar \\
\hline $\begin{array}{l}\text { İhracat engellerinin } \\
\text { arkasındaki kurumlar }\end{array}$ & $\% 38$ & $\% 36$ & $\% 26$ \\
\hline
\end{tabular}

Tablo 4'te ihracat engellerinin arkasındaki kurumlara ilişkin kodlamalara temel olan katılımcı ifadelerine ait örnekler sunulmaktadır. 
Ç. Baskıc1 - Y. Ercil 11/3 (2019) 1854-1865

Tablo 4. Kurum Kodlamalarına İlişkin Katılımcı İfadeleri

Bilişsel kurumlar Düzenleyici kurumlar Normatif kurumlar

K1: İhracat geliştirmede uzmanlığımız ve deneyimimiz yok. Nereden başlamamız gerektiğini bilmiyoruz.

K2: Yabanci pazar firsatlarmı doğru tespit etmekte zorlaniyoruz.
K7: İhracat bedellerinin ülkeye transferinde problem yaşıyoruz.

K10: İhracat kredilerinde yerel bankaların eksikliği...
K20: Avrupa pazarında Türkiye'ye güven sikintisı var.

K22: Ülke politikaları ve görünüşü bizi ihracatçı pazarlarında dezavantajlı yapabilir.

İhracat engellerinin oluşmasına neden olan kurumların engeller düzeyindeki dağılımı Tablo 5 'te sunulmaktadır. Buna göre kaynak engellerinin nedeni olarak görülen kurumların \%36,84'ü düzenleyici, \%31,58'i bilişsel ve \%31,58'i normatiftir. Dış kaynaklı engeller açısından aynı değerlendirme yapıldığında kaynak engellerinde olduğu gibi düzenleyici kurumlar \%63,16'lık oranla ilk sırada yer almaktadır. Prosedür engelleri için ilk sırada düzenleyici kurumlar, bilgi ve deneyim engellerinde ise bilişsel kurumlar yer almaktadır.

Tablo 5. Engeller ve Kurumlar (Genel) (\%)

Bilişsel kurumlar

Düzenleyici kurumlar

Normatif kurumlar

\begin{tabular}{lccc}
\hline Kaynak engelleri & 31,58 & 36,84 & 31,58 \\
Dış kaynaklı engeller & 10,53 & 63,16 & 26,32 \\
Prosedür engelleri & 33,33 & 44,44 & 22,22 \\
Bilgi ve deneyim & 83,33 & 8,33 & 8,33 \\
engelleri & & & \\
\hline
\end{tabular}

Yöneticilerin verdikleri cevaplara daha ayrıntılı bakıldığında farklı kurumların aynı engellere neden olduğu görülmektedir. Örneğin kaynak engelleri düzenleyici kurumlardan kaynaklanabilirken aynı zamanda kişilerin bilgi düzeyleri ile ilişkili olan bilişsel kurumlardan da kaynaklanabilmektedir. Başka bir bakış açısından aynı kurumlar farklı engellerin nedeni olabilir. Örneğin bilişsel kurumlar hem kaynak engellerinin hem de prosedür engellerinin nedenidir.

Tablo 6'da ihracat engellerinin dörtlü sınıflandırmasına göre engellerin arkasındaki kurumlara ilişkin kodlamalara temel olan katılımcı ifadelerine ait örnekler sunulmaktadır.

Tablo 6. Engeller ve Kurum Kodlamalarına İlişkin Katılımcı İfadeleri

Engeller-Kurumlar

Kaynak engelleri-Düzenleyici kurumlar

Kaynak engelleri-Bilişsel kurumlar

Dış kaynaklı engeller-Normatif kurumlar

Dış kaynaklı engeller-Normatif kurumlar

Prosedür engelleri-Bilişsel kurumlar

Prosedür engelleri-Düzenleyici kurumlar

Bilgi ve deneyim engelleri-Bilişsel kurumlar

Bilgi ve deneyim engelleri-Bilişsel kurumlar
Katılımc ifadeleri

K10: İhracat kredilerinde yerel bankalarm eksikliği...

K1: İhracat geliştirmede uzmanlı̆̆ımız ve deneyimimiz yok. Nereden başlamamız gerektiğini bilmiyoruz.

K5: Rekabet dış engeller açısından çok önemlidir. Dış engeller analiz edilmeden rekabet edilemez.

K8: Dış ülkeler ile iyi olmayan siyasi ilişkilerin ihracat üzerindeki etkileri aşılamaz...

K9: Her şey prosedür, engelleri aşamıyorum.

K23: Anlaşmalar...

K19: Yabanci pazar firsatlarm tespit edemiyorum.

K2: Yabancı pazar firsatlarını doğru tespit etmekte zorlaniyoruz. 


\section{Sonuç ve Tartışma}

Çalışmanın sonuç ve tartışma kısmı iki bölümden oluşmaktadır. İlk bölümde çalışmanın kuramsal bulgularının teorik ve pratik alandaki genel tartışmalarına yer verilirken ikinci bölümde ise örneklemin içinde bulunduğu bağlama özel tartışmalara yer verilmiştir.

Teorik ve pratik alandaki genel sonuç ve tartışmalar. Çalışma bulguları ile engellerin her birinin ortaya çıkmasına neden olan farklı kurumların varlığı tespit edilmiştir. Bu durum ihracat engellerinin literatürdeki gibi standart sınıflandırmaları ve engellere ilişkin standart çözüm önerileri (Hwang ve Boo, 2018; Katsikeas ve Morgan, 1994; Leonidou, 2004; Leonidou, 2000; Pinho ve Martins, 2010; Roy vd., 2016; Suàrez-Ortega, 2003) olamayacağını göstermektedir. Bu çalışmanın ışığında her bir ihracat engeline yönelik kurumların hangi ağırlıkta etkide olduğunu görmek mümkün olmuştur. Ancak belirtilmelidir ki her ülkenin kurumsal çevresinin farklı olmasından dolayı bu ağıllıkların örneklemden örnekleme değişeceği beklenmelidir. Bu durumda engelleri ortadan kaldırmaya yönelik jenerik politikaların üretilmesi zorlaşmakta, vaka özelinde politika uygulamalarına gidilmesinin önemi ortaya çıkmaktadır.

Çalışmada geliştirilen kuramsal bakış ile engellerin nedenlerinin kurumlar özelinde değerlendirilmesi mümkün olmuş, engellerin ortaya çıkmasında somut boyutların yanında farkındalık ya da değer yargıları gibi soyut boyutların olduğu görülebilmiştir. Örneğin literatürde kaynak engelleri çoğunlukla ihracat alanında uzmanlık eksikliği, işletme sermayesi finansmanı eksikliği, ihracat kredilerinde yerel bankaların eksikliği gibi bir zayıflık halini ifade etmektedir (Kahiya vd., 2014). Çalışmanın sonuçları kaynak engellerinin yalnızca düzenleyici değil bilişsel ve normatif boyutlarının da olabileceğini ortaya koyarak engellerin nedenlerinin karmaşık doğasına dikkat çekici niteliktedir. Somut tedbirler alarak bahsi geçen eksikliği gidermeye çalışan politika yapıcılarının büyük resmi görmekten uzaklaşabilecekleri büyük olasilıktadir.

Çalışmanın sonuçlarından olan engellerin sıralaması, literatürün büyük çoğunluğunun ortaya koyduğu sıralama yaklaşımlarının zaman-bağlam sınırlı olduğu iddiasını da ortaya çıkarmıştır. Sıralamaların, arkasındaki kurumlar nedeniyle değişim içinde olacağı açıktır. Engellerin öncelik sıralaması ile bunların arkasındaki nedenlerin kaldıraç güçleri arasındaki farklılık göz ardı edildiğinde kuramsal olarak yanlış değerlendirmede bulunma olasılığı artabilir. Ortaya konulacak bir yanlış teşhis ise engelleri giderme çabasında başarısızlıkla sonuçlanabilecektir. Bu açıdan çalışmada ulaşılan kuramsal çerçeve doğru teşhislerin oluşturulmasına yardımcı olacaktır.

Örneklem bağlamında özel sonuç ve tartışmalar. Genel tartışma kısmında da sunulduğu üzere araştırmaya katılan yöneticiler ihracatlarının önünde iki önemli engel algılamaktadırlar. Bunlardan ilki kaynak engelleri, ikincisi ise dış kaynaklı engellerdir. Yöneticiler açısından kaynak engellerinin nedeni olarak ilk sırada düzenleyici kurumlar yer almaktadır. Düzenleyici kurumlar formel bir otorite tarafından kurulması gereken kurallara işaret ettiğinden doğrudan politika yapıcıları ilgilendiren bir konudur. Buna göre kaynak engellerinin işletmeler tarafından aşılmasında veya bir engel olarak görülmemesinde devlet müdahalesine ihtiyaç duyulmaktadır. Örneğin devlet çeşitli düzenlemeler ve kanunlarla işletmeleri kaynaklar açısından destekleyebilir, işletmelerin ihracat kredilerine daha kolay ulaşmalarını sağlayacak mekanizmalar oluşturabilir ve ihracat teşvik ajansları kurarak ihtiyaç duyulan kaynaklar konusunda yardımlar sağlayabilir (Francis ve Collins-Dodd, 2004; Freixanet, 2012; Kang, 2011; Luo vd., 2010; Wang vd., 2017). Bu noktada ihracat yapan işletmelerin kaynak ihtiyaçları hedef ülkeler özelinde analiz edilerek desteklenebilir. Bununla birlikte bilişsel kurumlar ve normatif kurumlar aynı düzeyde kaynak engellerinin nedenleri olarak tespit edilmiştir. Bilişsel kurumların bir ülkedeki kişilerin bilgi ve yetenekleri anlamına geldiği göz önüne alınırsa kaynak engelleri kaynağa ilişkin bilgi ve yeteneklerin yetersizliğinden ortaya çıkmaktadır. Bu yetersizliği gidermeye yönelik ilgili kurumlar tarafından gerçekleştirilecek çeşitli uygulamalara ihtiyaç duyulmaktadır. Normatif kurumlar açısından doğrudan yöneticilerin değerleri, normları ve inançları kaynak engelini ortaya çıarmaktadır. Bu noktada ihracatçı birlikleri gibi çatı örgütlerin işletmelerle yapacağı projeler ve çalışmalarla normatif kurumların oluşumu analiz edilebilir ve politikalar geliştirilerek bunların engel nitelikleri ortadan kaldırılabilir.

Dış kaynaklı engellerin işletmenin dışında ve dolayısıyla kontrol edilemeyen unsurları kapsadığı düşünüldüğünde bu engellerin aşılmasında işletmeler politika yapıcılarının desteğine veya müdahalesine gereksinim duymaktadır. Çalışmada, bu desteğin veya müdahalenin öncelikli olarak düzenleyici kurumlara 
yapılması sonucu ortaya çıkmıştır. Yabancı kısıtlamalar ve düzenlemeler, diş pazarlarda güçlü rekabet, tarifeler ve tarife dışı engeller gibi tüm dış kaynaklı engellerin aşılmasında daha fazla devlet düzenlemesine ihtiyaç olabileceği görülmüştür.

Yöneticilerin karşılaştıkları prosedür engellerinin ortaya çıkmasında ilk sırada düzenleyici kurumlar yer almaktadır. İhracat prosedürlerinin anlaşılması, ihracat belgelerinin hazırlanması, yabancı distribütörlerin bulunması gibi unsurlardan oluşan bu engelleri işletmelerin yıllar içinde edindiği bilgi ve deneyimle aşması beklenir. Ancak yöneticiler bu engellerin nedeni olarak düzenleyici kurumları görmeye devam etmektedir. $\mathrm{Bu}$ durum yöneticilerin prosedür engellerini sistemsel bir sorun olarak algılamasından kaynaklanıor olabilir. Bununla birlikte işletmeler bu engelin oluşmasında ikinci sırada bilişsel kurumları görmektedir. Leonidou (2004) çalışmasında ihracat yapan küçük işletmeler için özel programların hazırlanması gerektiğini vurgulamaktadır. Bu programlarda ihracat prosedürlerine yönelik eğitim, seminer ve çalıştayların yapılması işletmelerin ihracat yapma becerilerini geliştirebilmesi açısından önem taşımaktadır.

Kaynak engellerinde olduğu gibi ihracata yönelik bilgi ve deneyim engellerinde de bir eksiklikten bahsedilmektedir. Bunlar içinde en önemlileri nasıl ihracat yapılacağı hakkında bilgi eksikliği, ihracat yardım programlarıyla ilgili bilgi eksikliği, yabancı pazar fırsatlarını tespit edememe ve yurtdışı hakkında bilgi eksikliği şeklinde sıralanabilir. Yöneticiler açısından bilgi ve deneyim engellerinin ortaya çıkma nedeni doğası gereği bilişsel kurumlardır. Dolayısıyla bilişsel kurumlara yönelik iyileştirmeler işletmelerin bu engelleri aşmasını kolaylaştıracaktır. Devlet bilgi sınırlılıklarının üstesinden gelme konusunda işletmelere yardımcı olarak işletmelerin uluslararasılaşma kabiliyetlerini ve istekliliklerini artırabilmektedir (Wang vd., 2012). Leonidou (2004) yukarıda bahsi geçen araştırmasında ihracata dönük pazar araştırması gibi konularda eğitim, seminer ve çalıştayların hazırlanmasının; yabancı pazarlarla ilgili teknik standartlar, müşteri listeleri ve ticari mevzuatlar hakkında bilgilerin sağlanmasının küçük işletmelerin ihracat yapma becerilerini geliştirebileceğini savunmaktadır. Pek çok ülkede hükümetler veya ticaret birlikleri tarafından sağlanan ihracat tanıtım programları özellikle KOBİ'ler için ihracat bilgisi açısından değerli bir kaynaktır (Francis ve Collins-Dodd, 2004). Örneğin Çin'de yatırım yapılacak ülkelerdeki kuralları içeren bilgi ve hizmet ağı, yatırım yapılacak ülkeler ve endüstriler ile ilgili rehber kataloglar bilişsel kurumların güçlendirilmesinde kullanılmaktadır (Luo vd., 2010).

Çalışma çeşitli kısıtlılıklara sahiptir. Bunlardan ilki araştırmaya dahil edilen işletmelerin tamamının Türk işletmeleri olmasıdır. Doğrudan yabancı yatırımların da dikkate alınması kurumsal çevrenin ihracat engelleri üzerindeki etkilerinin daha ayrıntılı anlaşılması açısından önem taşımaktadır. Ayrıca araştırmaya farklı sektörlerde faaliyet gösteren işletmeler dahil edilmiştir. Her sektör için engellerin ve nedeni olarak kurumların belirlenmesi, politika yapıcılar açısından sektöre özel önlemlerin alınmasını mümkün kılabilecektir.

Çalışmada elde edilen bulgular ışığında kurumların ihracat engelleri üzerindeki ağırlıklı rolü incelenmiştir. Böylece ihracatın önündeki engellerin niteliğinin tanımlanması ve tartışılması mümkün olmuştur. Bankalar, devlet, politika yapıcılar vb. örgütlerin ve aktörlerin bulgularda tanımlanan engellere bakışı gelecekteki çalışmalara bırakılmıştır. Bu alanda yapılacak çalışmalarla konunun daha derinliğine analizinin mümkün olacağı açıktır.

\section{Kaynakça}

Arteaga-Ortiz, J. and Fernández-Ortiz, R. (2010). Why don't we use the same export barrier measurement scale? An empirical analysis in small and medium-sized enterprises. Journal of Small Business Management, 48(3), 395-420.

Barney, J. (1991). Firm resources and sustained competitive advantage. Journal of Management, 17(1), 99-120.

Bazuchi, K. R., Zacharias, S. A., Broering, L. W., Arreola, M. F. and Bandeira-de-Mello, R. (2013). The role of home country political resources for Brazilian multinational companies. Brazilian Administration Review, 10(4), 415-438.

Bruton, G. D. and Ahlstrom, D. (2003). An institutional view of China's venture capital industry: Explaining the differences between China and the West. Journal of Business Venturing, 18(2), 233-259. 
Boddy, C. R. (2016). Sample size for qualitative research. Qualitative Market Research: An International Journal, 19(4), 426-432.

Cahen, F. R., Lahiri, S. and Borini, F. M. (2016). Managerial perceptions of barriers to internationalization: An examination of Brazil's new technology-based firms. Journal of Business Research, 69(6), 1973-1979.

Cardoza, G., Fornes, G. and Xu, N. (2012). Institutional determinants of Chinese SMEs' internationalization: The case of Jiangsu Province. School of Sociology, Politics and International Studies University of Bristol Working Paper.

Francis, J. and Collins-Dodd, C. (2004). Impact of export promotion programs on firm competencies, strategies and performance: The case of Canadian high-technology SMEs. International Marketing Review, 21(4/5), 474-495.

Freixanet, J. (2012). Export promotion programs: Their impact on companies' internationalization performance and competitiveness. International Business Review, 21, 1065-1086.

Gao, G., Murray, J. Y., Kotabe, M. and Lu, J. (2010). A "strategy tripod" perspective on export behaviors: Evidence from domestic and foreign firms based in an emerging economy. Journal of International Business Studies, 41(3), 377-396.

Garrido, E., Gomez, J., Maicas, J. P. and Orcos, R. (2014). The institution-based view of strategy: How to measure it. BRQ Business Research Quarterly, 17(2), 82-101.

Guest, G., Bunce, A. and Johnson, L. (2006). How many interviews are enough? An experiment with data saturation and variability. Field Methods, 18(1), 59-82.

Hitt, M. A., Ahlstrom, D., Dacin, M. T., Levitas, E. and Svobodina, L. (2004). The institutional effects on strategic alliance partner selection in transition economies: China vs. Russia. Organization Science, 15(2), 173-185.

Hwang, J.-A. and Boo, K.-J. (2018). Overseas expansion of South Korean renewable energy firms: Status and barriers. Renewable and Sustainable Energy Reviews, 81, 2862-2869.

İnan, H. ve Nakıboğlu, B. (2009). KOBİlerin ihracatta karşılaştıkları engellerin belirlenmesine yönelik mobilya sektöründe gerçekleştirilen bir araştırma. Ç.Ü. Sosyal Bilimler Enstitüsü Dergisi, 18(2), 228246.

Johanson, J. and Vahlne, J. (1990). The mechanism of internationalisation. International Marketing Review, 7(4), 11-24.

Ju, M., Zhao, H. and Wang, T. (2014). The boundary conditions of export relational governance: A "strategy tripod" perspective. Journal of International Marketing, 22(2), 89-106.

Kahiya, E. T. (2013). Export barriers and path to internationalization: A comparison of conventional enterprises and international new ventures. Journal of International Entrepreneurship, 11(1), 3-29.

Kahiya, E. T. and Dean, D. L. (2016). Export stages and export barriers: Revisiting traditional export development. Thunderbird International Business Review, 58(1), 75-89.

Kahiya, E. T., Dean, D. L. and Heyl, J. (2014). Export barriers in a changing institutional environment: A quasi-longitudinal study of New Zealand's manufacturing exporters. Journal of International Entrepreneurship, 12(4), 331-364.

Kang, K. (2011). Overseas network of export promotion agency and export performance: The Korean case. Contemporary Economic Policy, 29(2), 274-283.

Kaprálová, B. (2017). Export barriers in Latin America according to companies. Scientific Papers of the University of Pardubice, 25(41), 55-66.

Katsikeas, C. S. and Morgan, R. E. (1994). Differences in perceptions of exporting problems based on firm size and export market experience. European Journal of Marketing, 28(5), 17-35.

Kelly, G. A. (1955). The psychology of personal constructs. NY: Norton. 
Leonidou, L. C. (2000). Barriers to export management: An organizational and internationalization analysis. Journal of International Management, 6(2), 121-148.

Leonidou, L. C. (2004). An analysis of the barriers hindering small business export development. Journal of Small Business Management, 42(3), 279-302.

Luo, Y., Xue, Q. and Han, B. (2010). How emerging market governments promote outward FDI: Experience from China. Journal of World Business, 45(1), 68-79.

Mavrogiannis, M., Bourlakis, M. A., Dawson, P. J. and Ness, M. R. (2008). Assessing export performance in the Greek food and beverage industry: An integrated structural equation approach. British Food Journal, 110(7), 638-654.

Morgan, R. E. and Katsikeas, C. S. (1997). Obstacles to export initiation and expansion. The International Journal of Management Science, 25(6), 677-693.

Morschett, D., Schramm-Klein, H. and Zentes, J. (2010). Strategic international management: Text and cases. Netherlands: Gabler.

Morse, J. M. (1995). The significance of saturation. Qualitative Health Research, 5, 147-149.

Munir, K. A. (2002). Being different: How normative and cognitive aspects of institutional environments influence technology transfer. Human Relations, 55(12), 1403-1428.

Neupert, K. E., Baughn, C. C. and Dao, L. T. (2006). SME exporting challenges in transitional and developed economies. Journal of Small Business and Enterprise Development, 13(4), 535-545.

North, D. C. (1990). Institutions, institutional change and economic performance. New York: Cambridge University Press.

North, D. C. (1991). Institutions. Journal of Economic Perspectives, 5(1), 97-112.

Patton, M. Q. (2002). Qualitative research \& evaluation methods. London: Sage Publications.

Paul, J., Parthasarathy, S. and Gupta, P. (2017). Exporting challenges of SMEs: A review and future research agenda. Journal of World Business, 52(3), 327-342.

Peng, M. W. (2002). Towards an institution-based view of business strategy. Asia Pacific Journal of Management, 19(2-3), 251-267.

Peng, M. W., Sun, S. L., Pinkham, B. and Chen, H. (2009). The institution-based view as a third leg for a strategy tripod. Academy of Management Perspectives, 23(3), 63-81.

Peng, M. W., Wang, D. Y. and Jiang, Y. (2008). An institution-based view of international business strategy: A focus on emerging economies. Journal of International Business Studies, 39(5), 920-936.

Pinho, J. C. and Martins, L. (2010). Exporting barriers: Insights from Portuguese small- and medium-sized exporters and non-exporters. Journal of International Entrepreneurship, 8(3), 254-272.

Porter, M. E. (1980). Competitive strategy: Techniques for analyzing. New York: The Free Press.

Roy, A., Sekhar, C. and Vyas, V. (2016). Barriers to internationalization: A study of small and medium enterprises in India. Journal of International Entrepreneurship, 14(4), 513-538.

Rutashobya, L. and Jaensson, J.-E. (2004). Small firms' internationalization for development in Tanzania: Exploring the network phenomenon. International Journal of Social Economics, 31(1/2), 159-172.

Scott, W. R. (1995). Institutions and organizations. Thousand Oaks, California: Sage Publications.

Shirokova, G. and Tsukanova, T. (2013). Impact of the domestic institutional environment on the degree of internationalization of SMEs in transition economies. The International Journal of Entrepreneurship and Innovation, 14(3), 193-204.

Silva, J. R., Franco, M. and Magrinho, A. (2016). Empirical investigation of the effects of industry type and firm size on export barriers. Journal of Business Economics and Management, 17(6), 1052-1065. 
Ç. Baskıc1 - Y. Ercil 11/3 (2019) 1854-1865

Suàrez-Ortega, S. (2003). Export barriers: Insights from small and medium-sized firms. International Small Business Journal, 21(4), 403-419.

Sullivan, D. and Bauerschmidt, A. (1988). Common factors underlying incentive to export: Studies in the European forest products industry. European Journal of Marketing, 22(10), 41-55.

Teece, D. J., Pisano, G. and Shuen, A. (1997). Dynamic capabilities and strategic management. Strategic Management Journal, 18(7), 509-533.

Wang, C., Hong, J., Kafouros, M. and Wright, M. (2012). Exploring the role of government involvement in outward FDI from emerging economies. Journal of International Business Studies, 43(7), 655-676.

Wang, X., Chen, A., Wang, H. and Li, S. (2017). Effect of export promotion programs on export performance: Evidence from manufacturing SMEs. Journal of Business Economics and Management, 18(1), 131-145.

Yamakawa, Y., Peng, M. and Deeds, D. L. (2008). What drives new ventures to internationalize from emerging to developed economies?. Entrepreneurship Theory and Practice, 32(1), 59-82. 